\title{
Effects of meal and incretins in the regulation of splanchnic blood flow
}

\author{
Jukka Koffert1,2,*, Henri Honka2,*, Jarmo Teuho, Saila Kauhanen³, Saija Hurme4, \\ Riitta Parkkola',5, Vesa Oikonen², Andrea Mari', Andreas Lindqvist ${ }^{7}$, Nils Wierup?, \\ Leif Groop ${ }^{7}$ and Pirjo Nuutila ${ }^{2,8}$
}

1Department of Gastroenterology, Turunmaa Hospital, Turku, Finland

${ }^{2}$ Turku PET Centre, University of Turku, Turku, Finland

${ }^{3}$ Division of Digestive Surgery and Urology, Turku University Hospital, Turku, Finland

${ }^{4}$ Institute of Biostatistics, University of Turku, Turku, Finland

${ }^{5}$ Department of Radiology, University of Turku and Turku University Hospital, Turku, Finland

${ }^{6}$ Institute of Neuroscience, National Research Council, Padua, Italy

${ }^{7}$ Department of Clinical Sciences, Lund University Diabetes Centre, Malmö, Sweden

${ }^{8}$ Department of Endocrinology, Turku University Hospital, Turku, Finland

*(J Koffert and $\mathrm{H}$ Honka contributed equally to this work)

\author{
Correspondence \\ should be addressed \\ to P Nuutila \\ Email \\ pirjo.nuutila@utu.fi
}

\begin{abstract}
Objective: Meal ingestion is followed by a redistribution of blood flow (BF) within the splanchnic region contributing to nutrient absorption, insulin secretion and glucose disposal, but factors regulating this phenomenon in humans are poorly known. The aim of the present study was to evaluate the organ-specific changes in BF during a mixedmeal and incretin infusions.

Design: A non-randomized intervention study of 10 healthy adults to study splanchnic BF regulation was performed.

Methods: Effects of glucose-dependent insulinotrophic polypeptide (GIP) and glucagonlike peptide 1 (GLP-1) infusions and mixed-meal were tested in 10 healthy, glucose tolerant subjects using PET-MRI multimodal imaging technology. Intestinal and pancreatic BF and blood volume (BV) were measured with ${ }^{15} \mathrm{O}$-water and ${ }^{15} \mathrm{O}$-carbon monoxide, respectively.

Results: Ingestion of a mixed-meal led to an increase in pancreatic and jejunal BF, whereas duodenal BF was unchanged. Infusion of GIP and GLP-1 reduced BF in the pancreas. However, GIP infusion doubled blood flow in the jejunum with no effect of GLP-1.

Conclusion: Together, our data suggest that meal ingestion leads to increases in pancreatic BF accompanied by a GIP-mediated increase in jejunal but not duodenal blood flow.
\end{abstract}

Endocrine Connections (2017) 6, 179-187

\section{Introduction}

The splanchnic region is a crucial regulator of metabolic homeostasis; and disturbances in the function of gut and pancreas predispose to impaired glucose regulation in the postprandial state $(1,2,3)$. After a meal, blood flow (BF) is redistributed in the splanchnic region to accommodate the absorption of nutrients in the gut, glucose delivery and insulin drainage to and from the pancreatic islets,
(C) 2017 The authors Published by Bioscientifica Ltd and hepatic metabolism $(4,5,6)$. In healthy humans, an increase of about $50-100 \%$ has been reported in the celiac (CA) and superior mesenteric artery (SMA) flow following meal ingestion (7), but it is not known how this increase in perfusion is distributed between the splanchnic organs.

After a meal plasma levels of several potential vasoactive substances increase (8). In rodents, 
experimental hyperglycemia increases and hypoglycemia decreases pancreatic islet perfusion (9). Moreover, incretins have been shown to regulate BF in the splanchnic and systemic circulation. When Kogire and co-workers (10) injected GIP to healthy dogs, they observed increased BF in SMA but not in CA, suggesting that GIP contributes to the redistribution of $\mathrm{BF}$ after a meal. Similar results have been reported for GLP-1 (11). However, the effects of incretin hormones on splanchnic BF distribution have not previously been studied in humans, most likely due to a lack of appropriate methods.

The measurement of BF distribution in the splanchic area has now been overcome by a multimodal imaging approach with positron emission tomography (PET) which enables the assessment of splanchnic BF and blood volume (BV) in an organ-specific manner in humans (12). We used PET/MRI with ${ }^{15} \mathrm{O}$-water and ${ }^{15} \mathrm{O}$-carbon monoxide tracers to assess intestinal and pancreatic $\mathrm{BF}$ and $\mathrm{BV}$, respectively. The present study was conducted to evaluate the physiological vascular changes occurring in the gut and pancreas after a mixed-meal and after intravenous infusions GIP and GLP-1.

\section{Subjects and methods}

\section{Subjects}

A total of 10 healthy subjects were recruited (Table 1 ). The subjects had a body-mass index (BMI) of $18-27 \mathrm{~kg} / \mathrm{m}^{2}$, fasting plasma glucose was below $6.1 \mathrm{mM}$ and they were aged between 18 and 60 years. Subjects were generally in good health, as determined by physical examination, screening laboratory measurements and medical history. Smoking was considered as an exclusion criterion for the study. Subject body weight was stable between the experiments and none of the subjects had experienced rapid weight change three months prior to the enrollment.

\section{Study approval}

The Ethics Committee of the Hospital District of Southwestern Finland approved the studies (ClinicalTrials. gov Identifier NCT01880827), and all subjects gave their written informed consent before participation.

\section{Research design}

We measured changes in splanchnic BF and BV after a mixed-meal test, GIP infusion, and GLP-1 infusion
Table 1 Subject characteristics.

\begin{tabular}{|c|c|}
\hline Parameter & $\begin{array}{c}\text { Median (IQR) } \\
\quad n=10\end{array}$ \\
\hline \multicolumn{2}{|l|}{ Anthropometrics } \\
\hline $\mathrm{M} / \mathrm{F}$ & $2 / 8$ \\
\hline Age (years) & $46(46-52)$ \\
\hline Weight (kg) & $63.57(59.3-66.5)$ \\
\hline BMI $\left(\mathrm{kg} / \mathrm{m}^{2}\right)$ & $23.1(21.8-24.1)$ \\
\hline Body fat (\%) & $25.6(23.8-30.0)$ \\
\hline Systolic BP (mmHg) & 136 (124-139) \\
\hline Diastolic BP (mmHg) & $88.4(83.8-93.8)$ \\
\hline Smoking $(n(\%))$ & $0(0)$ \\
\hline Diabetes $(n(\%))$ & $0(0)$ \\
\hline \multicolumn{2}{|l|}{ Biochemical data } \\
\hline Fasting glucose (mM) & $5.1(4.9-5.2)$ \\
\hline 2-h glucose (mM) & $6.1(5.3-6.9)$ \\
\hline $\mathrm{HbA} 1 \mathrm{c}(\mathrm{mmol} / \mathrm{mol})$ & $33.0(30.0-33.9)$ \\
\hline Fasting insulin (U/L) & $4.5(3.0-5.8)$ \\
\hline \multicolumn{2}{|l|}{ Insulin sensitivity indices } \\
\hline $\mathrm{HOMA}_{\mathrm{IR}}$ (fraction) & $1.0(0.7-1.3)$ \\
\hline 2-h OGIS (mL/min $\left./ \mathrm{m}^{2}\right)$ & $458(429-481)$ \\
\hline \multicolumn{2}{|l|}{$\beta$-Cell function parameters } \\
\hline Basal ISR (pM/min/m²) & $66.9(54.1-77.0)$ \\
\hline Glucose sensitivity (pM/min/m²/mM) & $82.9(63.1-91.8)$ \\
\hline Potentiation factor ratio (dimensionless) & $1.6(1.2-3.2)$ \\
\hline
\end{tabular}

2-h OGIS, oral glucose insulin sensitivity index; GIP, glucose-dependent insulinotrophic peptide; GLP-1, glucagon-like peptide 1; HbA1C, glycated hemoglobin; $\mathrm{HOMA}_{\mathbb{R}}$, homeostatic model assessment for insulin resistance; ISR, insulin secretion rate.

(Supplementary Fig. 1, see section on supplementary data given at the end of this article). Prior to PETstudies a routine 75-g 2-h OGTT was performed to all subjects. Subjects were imaged in the supine position with a combined PET/MRI scanner Philips Ingenuity (Philips Healthcare) with $38 \times 38 \mathrm{~cm}$ axial field-of-view (13) after an overnight fast. Two peripheral catheters were placed in the antecubital veins: one for blood sampling and the other one (in the contralateral arm) for incretin infusions and ${ }^{15} \mathrm{O}$-water bolus injections. The lines were flushed with constant saline infusion. Baseline ${ }^{15} \mathrm{O}$-water and ${ }^{15} \mathrm{O}$-carbon monoxide PETacquisition and whole-body MRI preceded the experiments. During the PET-studies, plasma levels of glucose, insulin, C-peptide, FFA, GIP and GLP-1 were measured at time points $0,15,30,45,60$ and $90 \mathrm{~min}$. Blood pressure and clinical well-being were monitored throughout the studies.

To assess pancreatic and gut BF, a dynamic PET scanning of $310 \mathrm{~s}$ (with variable frame times) was performed following an intravenous bolus injection of ${ }^{15} \mathrm{O}$-water. Effective radiation dose per ${ }^{15} \mathrm{O}$-water injection was $0.47 \mathrm{mSv}$. The total injected amount of radioactivity was 491(462-515) MBq and radiochemical purity of the

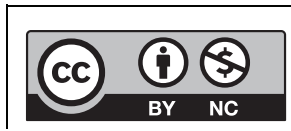

This work is licensed under a Creative Commons Attribution-NonCommercial 4.0 International License. 
radiotracer always exceeded 95\%. To study the changes in pancreatic and gut BV, subjects inhaled room air mixed with $0.14 \%{ }^{15} \mathrm{O}$-labeled carbon monoxide (CO) through a three-way inhalation flap-valve. The inhalation lasted for two minutes, the total radioactivity dose being $0.57 \mathrm{mSv}$, and the total administered amount of radioactivity was 726 (688-770) MBq. After the administration, another two minutes was allowed for the $\mathrm{CO}$ to combine with hemoglobin before the 4-min static PET scan (Supplementary Fig. 2).

Pancreatic and gut BF were calculated from ${ }^{15} \mathrm{O}$-water derived data by using a one-tissue compartment model (Fig. 1F) (14). Intestinal TACs were corrected for a delay between arterial and target tissue radioactivity, whereas delay correction was not considered necessary for pancreas.

Pancreatic and gut BVs were calculated from ${ }^{15} \mathrm{O}$-carbon monoxide derived data using the following mathematical formula:

$$
V_{\mathrm{B}}=100 \times C_{\text {PET }} \times\left(C_{\text {BLOOD }} \times \rho_{\text {tissue }} \times 0.85\right)^{-1}
$$

wherein $V_{\mathrm{B}}$ is the $\mathrm{BV}$ of the tissue region (in $\mathrm{mL} 100 / \mathrm{g}$ ), $C_{\mathrm{PET}}$ and $C_{\mathrm{BLOOD}}$ are the radioactivities in the tissue and blood (in $\mathrm{Bq} / \mathrm{mL}$ ), respectively, $\rho_{\text {tissue }}$ is the tissue density $(1.045,1.047$ and $1.042 \mathrm{~g} / \mathrm{mL}$ for pancreas, duodenum and jejunum, respectively) and 0.85 represents the tissueto-large vessel hematocrit ratio (15). BF and BV values were corrected to the organ volume. Pancreatic volume was measured in a manual fashion from abdominal MR images whereas conventional values of $556.6 \mathrm{~mL}$ and $57.3 \mathrm{~mL}$ were used for jejunum and duodenum, respectively (15).

\section{Mixed-meal testing}

After baseline scans, a mixed-meal solution was administered orally during a $10-\mathrm{min}$ period in a supine position. The mixed-meal (Nutridrink, Nutricia Advanced Medical Nutrition, Amsterdam, Netherlands) contained $250 \mathrm{kcal}$ energy, and consisted of 40, 6 and $9 \mathrm{~g}$ of carbohydrates, fat and protein, respectively. During the 90 -min time period ${ }^{15} \mathrm{O}$-water and ${ }^{15} \mathrm{O}$-carbon monoxide PET-scans were repeated twice (Supplementary Fig. 2A): at 20 and 50 min postingestion for ${ }^{15} \mathrm{O}$-water and at 40 and $70 \mathrm{~min}$ postingestion for ${ }^{15} \mathrm{O}$-carbon monoxide, respectively.

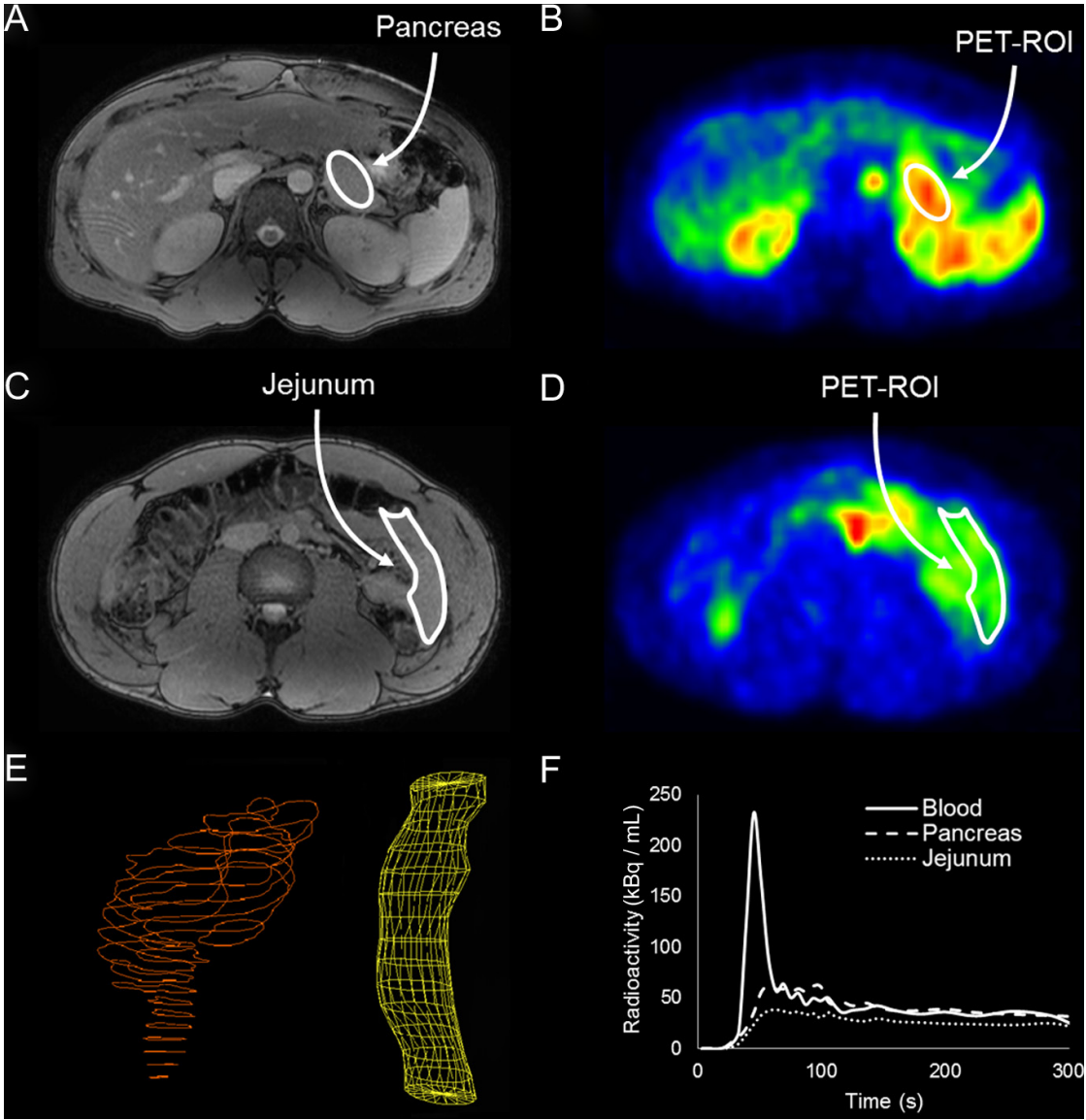

Figure 1

Non-invasive estimation of splanchnic blood flow (BF) at baseline and during the experiments using positron emission tomography (PET). ( $A, B, C$ and $D$ ) An example of co-registered abdominal $\mathrm{MRI}$ and ${ }^{15} \mathrm{O}$-water PET image at the levels of second and fifth lumbar vertebrae, respectively. Pancreas and gut were identified from MRI image and the regions-of-interest (ROI) were reproduced into $P E T$ image. (E) Tissue-specific time-activity curves (TAC) were extracted from 3-dimensional ROIs in a manual fashion. Pancreatic ROI, orange polygon; gut ROI, yellow cylinder. (F) Pancreatic and intestinal BFs were calculated using one-tissue compartment analysis with an image-derived input function from abdominal aorta. 


\section{Incretin infusion experiments}

Incretins were dissolved in sterilized water with $2 \%$ human serum albumin in the hospital pharmacy and were administered into the peripheral vein via a cannula with syringe pumps after baseline PET-scans. For GIP infusion, after baseline scans a constant 75-min GIP $_{1-42}$ (Bachem Holding AG, Bubendorf, Switzerland) infusion was started at a rate of $4.0 \mathrm{pmol} / \mathrm{kg} / \mathrm{min}$ and the rate was halved at the 15-min time point (16). The variation in infusion rate was performed with the intention to reproduce physiological concentrations of GIP normally present in the splanchnic circulation after the meal ingestion. For GLP-1 infusion, after baseline scans a constant 75-min GLP-1 (Bachem Holding AG) infusion was started at the rate of $0.75 \mathrm{pmol} /$ $\mathrm{kg} / \mathrm{min}$ and the rate was maintained throughout the experiment (17). ${ }^{15} \mathrm{O}$-water and ${ }^{15} \mathrm{O}$-carbon monoxide PET-scans were performed as described above.

\section{Image processing, PET and MRI analysis}

All data were corrected for dead time, decay and measured photon attenuation and reconstructed in a $256 \times 256$ matrix. Regional time-activity curves (TAC) were obtained from the 3-dimensional regions-of-interest (ROIs) drawn manually in the pancreatic parenchyma, duodenum and jejunum (Fig. 1A, B, C, D and E) using the Carimas 2.9 software (Turku PET Centre, downloadable at http:// turkupetcentre.fi). An image-derived input function was obtained from the abdominal aorta, as described previously (18). For reliable analysis, MRI scans were used as an anatomical reference (19).

\section{Quantitation of insulin sensitivity and secretion}

Homeostatic model assessment for insulin resistance $\left(\mathrm{HOMA}_{\mathrm{IR}}\right)$ was calculated as Gluc $\times$ Ins: 22.5 from fasting samples. Moreover, insulin sensitivity was expressed as 2-h oral glucose insulin sensitivity index (OGIS) reflecting glucose clearance during hyperinsulinemic conditions (20). Basal and total (absolute) insulin secretion rate (ISR) during meal-testing was derived from deconvolution of C-peptide kinetics (21), and $\beta$-cell function modeling (glucose sensitivity, rate sensitivity and $\beta$-cell potentiation) was applied to the data.

\section{Biochemical analyses}

During standard oral glucose tolerance test (OGTT) and experiments, blood was collected to lithium heparin and EDTA tubes and was stored at $-80^{\circ} \mathrm{C}$ until further analyses. Additional blood samples were collected in chilled EDTA tubes pretreated with $25 \mathrm{mg}$ of DPP-IV inhibitor (Diprotin-A, Sigma-Aldrich); and 2000 KIE of trypsin inhibitor (Trasylol, Bayer AG) were added to chilled EDTA tubes before blood sampling. Determination of plasma glucose, insulin, C-peptide, FFA, HbA1c and cholesterol levels are described elsewhere (12). Total plasma GIP and active GLP-1 was measured using an enzyme-linked immunosorbent assay (ELISA) from Merck Millipore. GIP and GLP-1 assays were performed according to the instructions provided by the manufacturers.

\section{Statistics}

The data are expressed as mean (interquartile range, IQR). Analyses of changes over time and between experiments (GIP infusion vs GLP-1 infusion) were performed using repeated measurements ANOVA; and Tukey-Kramer method was used to adjust the $P$ values of paired comparisons. To investigate the association of independent factors and splanchnic flow during mixedmeal test, a linear regression analysis was performed. The differences in time-corrected AUCs between experiments were calculated using paired $t$ test (within study arms) and Mann-Whitney $U$ test (between study arms); and Bonferroni's method was used to adjust the $P$ values of paired comparisons. The normality of residuals was checked for justification of the analyses. Pearson's or Spearman's correlation coefficients were calculated depending on the normality of the data. A value of $P<0.05$ was considered statistically significant. Statistical analyses were performed using the SAS System for Windows, version 9.4 (SAS Institute, Cary, NC, USA).

\section{Results}

\section{The metabolic effects of a mixed-meal test}

Fifteen minutes after ingestion of the mixed-meal plasma glucose, serum insulin (Fig. 2A and B) and C-peptide were increased. Simultaneously, plasma GIP levels increased and reached a plateau at $30 \mathrm{~min}$ postingestion (Fig. 2C). In contrast, plasma GLP-1 (Fig. 2C) remained unchanged. In concert with increased insulin appearance, serum FFA levels decreased from $0.75(0.53-0.96)$ to 0.36 $(0.17-0.55) \mathrm{mM}(P=0.007)$ within 90-min.

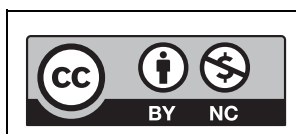

This work is licensed under a Creative Commons Attribution-NonCommercial 4.0 International License. 

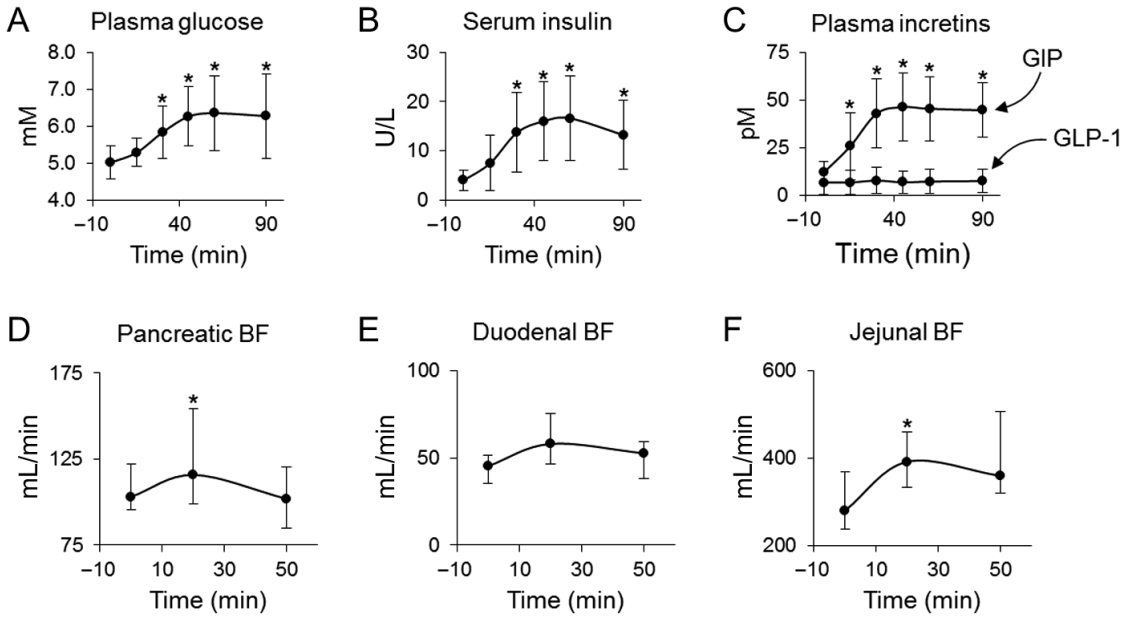

\section{Figure 2}

Metabolic and splanchnic vascular changes after mixed-meal ingestion. After ingestion of a mixed-meal, an increase in plasma levels of glucose (A) and insulin (B) was observed. Mixed-meal ingestion provoked a rapid and sustained increase in plasma GIP levels (C; black balls), whereas no change in plasma GLP-1 levels was observed (C; white balls). A significant increase in pancreatic (D) and jejunal (F) BF was seen 20-min postingestion whereas duodenal $B F(E)$ was unaffected by mixed-meal ingestion. Both pancreatic (D) and jejunal (F) BF were normalized at 50-min postingestion. Data are median (IQR), $n=10$, ${ }^{*} P<0.05$ vs baseline in repeated measurements ANOVA with Tukey-Kramer correction.

\section{The splanchnic vascular effects of a mixed-meal test}

At baseline, the median (IQR) pancreatic, duodenal and jejunal BF were 1.57 (1.46-1.78), 0.79 (0.70-0.92) and $0.54(0.43-0.66) \mathrm{mL} / \mathrm{mL} / \mathrm{min}$, respectively. Mixed-meal ingestion increased pancreatic and jejunal $\mathrm{BF}$ by 1.17 - and 1.68 -fold ( $P=0.016$ and 0.023 for time factor, respectively) at $20 \mathrm{~min}$, whereas no change in duodenal BF was observed $(P=0.307$ for time factor) (Fig. 2D, E and F). Pancreatic $\mathrm{BF}$ returned to baseline at $50 \mathrm{~min}$ despite plasma glucose concentrations still being elevated. In contrast, jejunal BF remained elevated during the whole test. Individual $\mathrm{BF}$ values in the pancreas but not in the intestine after the meal (both 20 or $50 \mathrm{~min}$ ) correlated with baseline values $\left(r_{\mathrm{P}}\right.$ range $\left.0.92-0.97, P<0.001\right)$. At baseline $\mathrm{BV}$ values were 14.2 (12.0-15.3), 16.9 (10.3-19.7) and 13.4 (9.53-17.4) $\mathrm{mL}$ $100 \mathrm{~g}$ in pancreas, duodenum and jejunum, respectively, and remained unchanged throughout the mixedmeal test.

\section{Interrelationships between metabolic and BF variables}

During the mixed-meal test, incremental area under the curve (iAUC) of glucose during the 90-min mixed-meal test was positively correlated with iAUC of GIP (Fig. 3A) confirming the glucose dependency of GIP-secretion. However, the same relationship was not observed between increase in glucose and GLP-1 $\left(r_{\mathrm{p}}=0.129, P=0.722\right)$, even though GLP-1 (iAUC) but not GIP response was positively correlated with glucose sensitivity $\left(r_{\mathrm{P}}=0.717, P=0.030\right)$ and with absolute insulin secretion rate (Fig. 3B). Neither total nor iAUC of pancreatic BF response during the mixed-meal test correlated with empirical- or modelderived parameters of $\beta$-cell function, or with insulin and C-peptide response. However, incremental glucose (Fig. 3C) and GIP $(r=0.730, P=0.040)$ responses were positively correlated with pancreatic BF response, whereas neither glucose nor incretins were associated with intestinal BF responses.

\section{The effect of infusion of GIP and GLP-1}

Supraphysiological levels of plasma GIP and GLP-1 were reached within $15 \mathrm{~min}$ after the start of the corresponding infusions (Fig. 4A and B), respectively, and this was accompanied by a sharp and transient increase in serum insulin (Fig. 4C) and C-peptide concentrations (data not shown). Decrease in plasma glucose was evident only during the GLP-1 infusion, but not during the GIP infusion (Fig. 4D). Compared to baseline values, pancreatic BF decreased similarly during
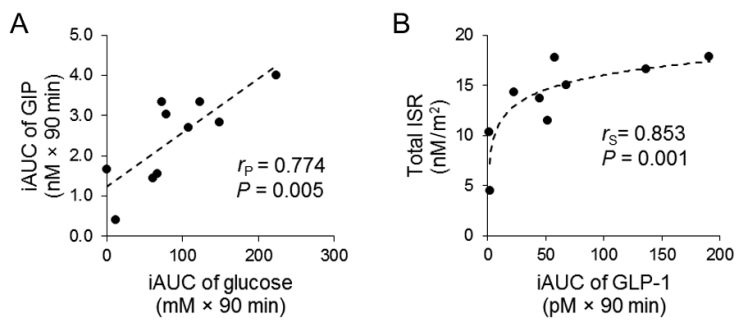

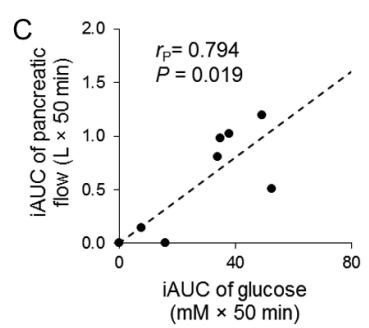

Figure 3

Relationships between metabolic variables and pancreatic BF during a mixed-meal test. (A) Plasma GIP and glucose correlated supporting the bifunctionality (i.e. absorption and GIP-secretion) of the foregut $(n=10)$. (B) GLP-1 response was correlated with total insulin secretion rate (ISR) during the meal $(n=9)$. (C) Increment in pancreatic flow correlated with glucose response $(n=8)$. iAUC, incremental area under curve; ISR, insulin secretion rate. http://www.endocrineconnections.org DOI: 10.1530/EC-17-0015 (c) 2017 The authors Published by Bioscientifica Ltd
This work is licensed under a Creative Commons Attribution-NonCommercial 4.0 International License. 
A

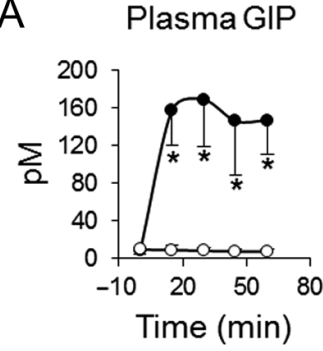

B Plasma GLP-1

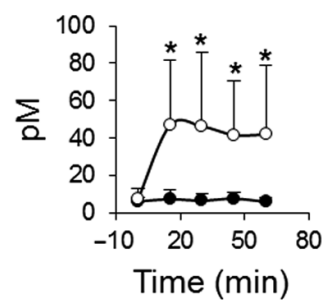

C

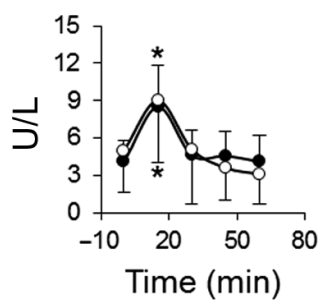

D Plasmaglucose

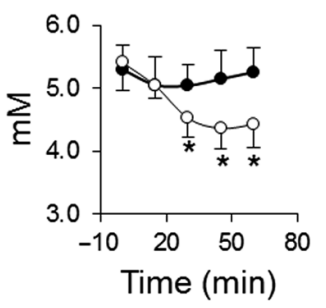

E

Pancreatic BF

$\mathrm{F}$

Duodenal BF

G Jejunal BF
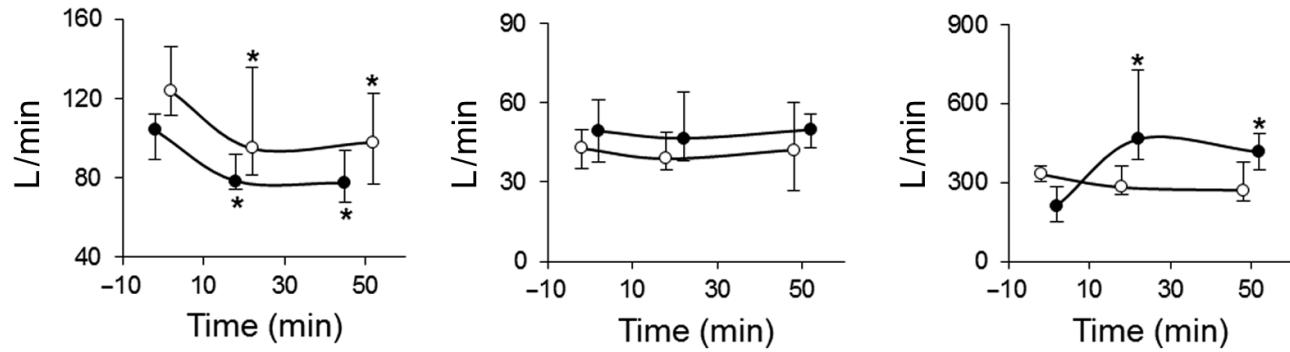

\section{Figure 4}

The effects of GIP (black dots) and GLP-1 (white dots) infusions on splanchnic BF. Supraphysiological concentrations of GIP (A) and GLP-1 (B) were reached within $15 \mathrm{~min}$ of start of the consequent infusion without affecting the levels of the uninfused incretin, respectively. Both incretins increased insulin levels transiently (C) whereas the decrease in plasma glucose was significant only during GLP-1 infusion (D). Infusion of GIP and GLP-1 led to a similar decrease in pancreatic BF rate (E). While infusions of GIP and GLP-1 unaltered duodenal BF (F), an increase in jejunal BF followed GIP but not GLP-1 infusion (G). Data are median (IQR), $n=10, * P<0.05$ vs baseline in repeated measurements ANOVA with Tukey-Kramer correction for individual interventions, $* * P<0.05$ vs baseline in repeated measurements ANOVA with Tukey-Kramer correction for pooled data.

GIP and GLP-1 infusion $(P<0.001$ for time factor and $P=0.745$ for time $\times$ intervention interaction, Fig. 4E). On the other hand, neither infusions had an effect on duodenal $\mathrm{BF}(P=0.756$ for time factor, and $P=0.906$ for time $\times$ intervention interaction; Fig. $4 \mathrm{~F})$. Jejunal $\mathrm{BF}$ was increased by 2.4 -fold during the GIP infusion $(P<0.001$ for time factor, Fig. $4 \mathrm{G}$ ) but it was unchanged during the GLP-1 infusion $(P=0.691$ for time factor, $P<0.001$ for time $\times$ intervention interaction). GIP and GLP-1 had no effect on pancreatic and intestinal BV. Decreases in plasma glucose after the GLP-1 infusions were not correlated with corresponding $\mathrm{BF}$ response in pancreas or intestine.

\section{Discussion}

The results of the present study demonstrate the adaptations in splanchnic BF during meal ingestion. Thus, a mixed-meal increased pancreatic and jejunal, but not duodenal BF. Infusion of GIP increased intestinal BF and reduced pancreatic blood flow. In contrast, infusion of GLP-1 diminished only pancreatic BF.

Here we utilized validated (12), cutting-edge molecular imaging methodology in ten healthy subjects and reported that jejunal and pancreatic BF in vivo are increased by approximately $70 \%$ and $20 \%$, respectively, after a meal ingestion. In 1980s Chou and Kvietys coworkers $(22,23)$ described the hierarchy of nutrients inducing intestinal hyperemia and showed that lipid and fat in combination with bile are the most potent flow inducers followed by glucose and proteins. In healthy individuals, the rate of gastric emptying is tightly regulated by small intestinal feedback, wherein acute hyperglycemia and elevated levels of GLP-1 are mutually involved $(24,25)$. There are several differences in the magnitude of regulation of flow between gut and pancreas. First, pancreatic flow response seems to be dependent only on the levels of circulating vasoactive substances such as glucose and GIP, and on neural factors (26), while the postprandial response of the gut seems largely regulated by a direct interaction between luminal contents and the gut mucosa. Second, the stimulated gut BF accommodates absorption and metabolic processes, such as waste removal (27). In contrast to the jejunum, duodenal BF remained unchanged during the mixed-meal test, suggesting that the mucosal acid concentration might be the dominant flow regulator in the duodenum (28).

The incretin hormones GIP and GLP-1 are released from the enteroendocrine cells of the fore- and hindgut, respectively, upon chyme and bile salt contact with the 
mucosa, resulting in a potentiation of glucose-stimulated insulin secretion (GSIS) and control of appetite and food intake $(29,30)$. Both the GIP (31) and GLP-1 (32) receptors (GIPR and GLP-1R) have been identified in the endothelial and smooth muscle cells of the arterioles and GLP-1 has been ascribed cardioprotective role by endothelium-dependent vasodilation $(32,33)$. While previous studies in cultured cells $(10,34)$ and in vivo in canines have suggested that incretins may regulate splanchnic BF kinetics in the absorptive state, the involvement of the incretins in humans is somewhat unclear as the levels of active incretin hormones in the peripheral circulation are lower than the minimum doses required to produce vasodilatation (27). However, local tissue concentrations of these hormones, especially in the prehepatic vasculature (35), are high enough to exert their vasoactive properties. The doses of GLP-1 and GIP used in our study resulted in modestly pharmacological plasma levels and were well tolerated.

Interestingly, GIP infusion had a dual effect on BF, with a prominent increase in jejunal BF, paralleled by a decrease in pancreatic BF. Both of the incretin infusions transiently stimulated insulin secretion, consistent with previous findings (36). The results presented here suggest that in humans GIP may prepare the hindgut for the increases in metabolic demand, accompanied by a parallel increase in insulin secretion. The increase in jejunal BF elicited by GIP was in agreement with animal studies documenting augmentation of SMA flow after GIP bolus administration (10), confirming identical regulation in man. Previous studies in conscious animals failed to show any vasodilatation in the gut wall arterioles in response to postprandial incretin levels (27), indicating that the observed GIP-induced gut hyperemia is likely caused by the elevation in SMA BF.

The splanchnic vascular effects of GLP-1 were modest when compared with those of GIP, and were evident only as a decrease in pancreatic BF. In contrast after the mixedmeal test, GLP-1 was positively associated with jejunal but not with pancreatic or duodenal BF response. This is likely the result of the luminal stimulation of the gut leading to simultaneous upregulation of flow and hormonal secretion, rather than a causal relationship between incretins and gut BF. Of note, active GLP-1 levels remained in the baseline after mixed-meal ingestion (Fig. 2C), likely due to low amount of carbohydrates being insufficient for eliciting a response in GLP-1 secretion. The observation that GLP-1 does not regulate intestinal BF in the absorptive state is in line with a previous study in healthy Wistar rats (37). The same authors showed that GLP-1 attenuated pancreatic BF only after glucose administration but not during fasting conditions (37). In the study done by Trahair and coworkers the co-administration of GLP-1 infusion in humans further enhanced increase in SMA BF elicited by intraduodenal (ID) glucose infusion, whereas plain GLP-1 infusion without ID glucose infusion led to decrement in SMA BF (38). This is in line with our present study where GLP-1 leads to decrement in pancreatic BF, a tributary organ of SMA. However, why the jejunal BF remained unchanged despite the decrease in SMA BF cannot be answered on the basis of the present study but it may be linked to autoregulation in the mucosal vascular bed.

In interpreting these results some potential limitations should be recognized. We did not measure cardiac output, gastric emptying, sympathetic activity and atrial natriuretic peptide (ANP), which may be of relevance (39). It was not possible to differentiate islet $\mathrm{BF}$ from the exocrine pancreas BF due to the current PET resolution which equates 25 -times the size of an average human islet (13). Consequently, the total pancreatic BF during the mixed-meal test may not reflect the exact vascular milieu in the islets. This may have curtained the link between islet BF, $\beta$-cell function, and insulin secretion during mixed-meal testing $(5,40)$. While the exocrine pancreatic $\mathrm{BF}$ is dependent on the afferent $\mathrm{BF}$ from the CA and its branches, islets have been shown to have more sophisticated vascular autoregulation $(9,11)$. Finally, two study subjects had IGT, which might have influenced the splanchnic flow. However, their splanchnic responses showed no statistical difference compared to non-insulin resistant study subjects.

In conclusion, the results of the present study demonstrate marked BF redistribution in the splanchnic vascular bed in response to a mixed-meal, due to an interaction of direct chyme contact, and elevations in plasma levels of glucose and incretin hormones, mainly GIP. Putative vascular effects of GLP-1 and GIP are likely to be more potent during postprandial and hyperglycemic conditions.

\section{Supplementary data}

This is linked to the online version of the paper at http://dx.doi.org/10.1530/ EC-17-0015.

\section{Declaration of interest}

The authors declare that there is no conflict of interest that could be perceived as prejudicing the impartiality of the research reported. http://www.endocrineconnections.org DOI: 10.1530/EC-17-0015
(C) 2017 The authors Published by Bioscientifica Ltd
This work is licensed under a Creative Commons Attribution-NonCommercial 4.0 International License. 
Funding

This study was conducted within the Finnish Centre of Excellence in Cardiovascular and Metabolic Diseases supported by the Academy of Finland, and grants from the Finnish Medical Foundation, Emil Aaltonen Foundation, Varsinais-Suomi Regional Fund, Finnish Cultural Foundation, Maud Kuistila Foundation, Orion Research Foundation, the Diabetes Research Foundation, Paavo Nurmi Foundation, the Gastroenterological Research Foundation, Paavo Ilmari Ahvenainen Foundation and Mary and Georg C. Ehrnrooth Foundation. N G is funded by a grant from Swedish Research Council project grant Dnr. 2013-22243, and grants from The Påhlsson, Crafoord, Swedish Diabetes, Diabetes Wellness Network Sweden Foundations. L G is funded by a grant from ERC (ERC adv res grant 26905), Swedish Research Council as well as a Linne grant to Lund University Diabetes Centre.

\section{Author contribution statement}

$\mathrm{J} \mathrm{K}$ and $\mathrm{H} \mathrm{H}$ contributed to the design of the study, acquired and researched data, and wrote the manuscript. J $\mathrm{T}$ contributed to image reconstruction development and analysis. S K contributed to the design of the study and discussion, researched data and edited the manuscript. $S \mathrm{H}$ researched data, made statistical analyses, and reviewed and edited the manuscript. R P, V O and A M offered technical support, and contributed to the discussion. $A \mathrm{~L}, \mathrm{~N} \mathrm{~W}$ and $\mathrm{L}$ G contributed to the design of the study and discussion, and edited the manuscript. P N was the guarantor of this work and, as such, had full access to all the data in the study and takes responsibility for the integrity of the data and the accuracy of the data analysis. All authors approved the final version of the manuscript.

\section{Acknowledgements}

The authors thank the staff of Turku PET Centre for all their expertise in the imaging analyses. Hanna Kivikoski and Lauri Laitinen are acknowledged for their help in the preparation of pharmaceutical infusates, and Jani Linden and Virva Saunavaara for their technical assistance. We are grateful to all the subjects who participated in the study. The results of this study were presented in a poster session at the American Diabetes Association (Alexandria, VA, United States) 75th Scientific Sessions in Boston, 5-9 June 2015, and in an oral session at the European Association for the Study of Diabetes (EASD, Düsseldorf, Germany) 51st Annual Meeting in Stockholm, 14-18 September 2015.

\section{References}

1 Butler PC \& Rizza RA. Contribution to postprandial hyperglycemia and effect on initial splanchnic glucose clearance of hepatic glucose cycling in glucose-intolerant or NIDDM patients. Diabetes 199140 73-81. (doi:10.2337/diab.40.1.73)

2 Holman RR. Assessing the potential for alpha-glucosidase inhibitors in prediabetic states. Diabetes Research and Clinical Practice $1998 \mathbf{4 0}$ (Supplement) S21-S25. (doi:10.1016/S0168-8227(98)00038-2)

3 Makinen J, Hannukainen JC, Karmi A, Immonen HM, Soinio M, Nelimarkka L, Savisto N, Helmio M, Ovaska J, Salminen P, et al. Obesity-associated intestinal insulin resistance is ameliorated after bariatric surgery. Diabetologia 201558 1055-1062. (doi:10.1007/ s00125-015-3501-3)

4 Matheson PJ, Wilson MA \& Garrison RN. Regulation of intestinal blood flow. Journal of Surgical Research 200093 182-196. (doi:10.1006/ jsre.2000.5862)

5 Carlsson PO \& Jansson L. Disruption of insulin receptor signaling in endothelial cells shows the central role of an intact islet blood flow for in vivo beta-cell function. Diabetes 201564 700-702. (doi:10.2337/db14-1523)

6 Meier JJ, Veldhuis JD \& Butler PC. Pulsatile insulin secretion dictates systemic insulin delivery by regulating hepatic insulin extraction in humans. Diabetes 200554 1649-1656. (doi:10.2337/ diabetes.54.6.1649)

7 Someya N, Endo MY, Fukuba Y \& Hayashi N. Blood flow responses in celiac and superior mesenteric arteries in the initial phase of digestion. American Journal of Physiology 2008294 R1790-R1796. (doi:10.1152/ajpregu.00553.2007)

8 Premen AJ, Kvietys PR \& Granger DN. Postprandial regulation of intestinal blood flow: role of gastrointestinal hormones. American Journal of Physiology 1985249 G250-G255.

9 Jansson L, Andersson A, Bodin B \& Kallskog O. Pancreatic islet blood flow during euglycaemic, hyperinsulinaemic clamp in anaesthetized rats. Acta Physiologica 2007189 319-324. (doi:10.1111/j.17481716.2006.01666.x)

10 Kogire M, Inoue K, Sumi S, Doi R, Takaori K, Yun M, Fujii N, Yajima $\mathrm{H} \&$ Tobe T. Effects of synthetic human gastric inhibitory polypeptide on splanchnic circulation in dogs. Gastroenterology 198895 1636-1640. (doi:10.1016/s0016-5085(88)80089-1)

11 Wu L, Olverling A, Huang Z, Jansson L, Chao H, Gao X \& Sjoholm A. GLP-1, exendin-4 and C-peptide regulate pancreatic islet microcirculation, insulin secretion and glucose tolerance in rats. Clinical Science 2012122 375-384. (doi:10.1042/CS20090464)

12 Honka H, Makinen J, Hannukainen JC, Tarkia M, Oikonen V, Teras M, Fagerholm V, Ishizu T, Saraste A, Stark C, et al. Validation of [18F] fluorodeoxyglucose and positron emission tomography (PET) for the measurement of intestinal metabolism in pigs, and evidence of intestinal insulin resistance in patients with morbid obesity. Diabetologia 201356 893-900. (doi:10.1007/s00125-012-2825-5)

13 Zaidi H, Ojha N, Morich M, Griesmer J, Hu Z, Maniawski P, Ratib O, Izquierdo-Garcia D, Fayad ZA \& Shao L. Design and performance evaluation of a whole-body ingenuity TF PET-MRI system. Physics in Medicine and Biology 201156 3091-3106. (doi:10.1088/00319155/56/10/013)

14 Kety SS \& Schmidt CF. Measurement of cerebral blood flow and cerebral oxygen consumption in man. Federation Proceedings 19465 264

15 Snyder WS CM, Nasset ES, Karhausen LR, Howells GP \& Tipton IH. Report of the Task Group on Reference Man. Oxford, UK: Pergamon Press, 1975.

16 Christensen M, Vedtofte L, Holst JJ, Vilsboll T \& Knop FK. Glucosedependent insulinotropic polypeptide: a bifunctional glucosedependent regulator of glucagon and insulin secretion in humans. Diabetes $2011603103-3109$. (doi:10.2337/db11-0979)

17 Plamboeck A, Holst JJ, Carr RD \& Deacon CF. Neutral endopeptidase 24.11 and dipeptidyl peptidase IV are both mediators of the degradation of glucagon-like peptide 1 in the anaesthetised pig. Diabetologia 200548 1882-1890. (doi:10.1007/s00125-005-1847-7)

18 Germano G, Chen BC, Huang SC, Gambhir SS, Hoffman EJ \& Phelps ME. Use of the abdominal aorta for arterial input function determination in hepatic and renal PET studies. Journal of Nuclear Medicine 199233 613-620.

19 Grubb RL Jr, Raichle ME, Higgins CS \& Eichling JO. Measurement of regional cerebral blood volume by emission tomography. Annals of Neurology 19784 322-328. (doi:10.1002/ana.410040407)

20 Mari A, Pacini G, Murphy E, Ludvik B \& Nolan JJ. A model-based method for assessing insulin sensitivity from the oral glucose tolerance test. Diabetes Care 200124 539-548. (doi:10.2337/diacare.24.3.539)

21 Eaton RP, Allen RC, Schade DS, Erickson KM \& Standefer J. Prehepatic insulin production in man: kinetic analysis using peripheral connecting peptide behavior. Journal of Clinical Endocrinology and Metabolism 198051 520-528. (doi:10.1210/jcem-51-3-520) http://www.endocrineconnections.org DOI: 10.1530/EC-17-0015 (c) 2017 The authors Published by Bioscientifica Ltd

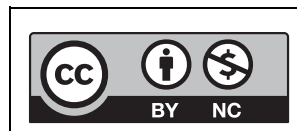

This work is licensed under a Creative Commons Attribution-NonCommercial 4.0 International License. 
22 Chou CC, Nyhof RA, Kvietys PR, Sit SP \& Gallavan RH Jr. Regulation of jejunal blood flow and oxygenation during glucose and oleic acid absorption. American Journal of Physiology 1985249 G691-G701.

23 Kvietys PR, Gallavan RH \& Chou CC. Contribution of bile to postprandial intestinal hyperemia. American Journal of Physiology 1980 238 G284-G288.

24 Rayner CK, Samsom M, Jones KL \& Horowitz M. Relationships of upper gastrointestinal motor and sensory function with glycemic control. Diabetes Care 200124 371-381. (doi:10.2337/diacare.24.2.371)

25 Brener W, Hendrix TR \& McHugh PR. Regulation of the gastric emptying of glucose. Gastroenterology $1983 \mathbf{8 5} 76-82$.

26 Jansson L. The regulation of pancreatic islet blood flow. Diabetes/ Metabolism Reviews 199410 407-416. (doi:10.1002/dmr.5610100405)

27 Chou CC \& Coatney RW. Nutrient-induced changes in intestinal blood flow in the dog. British Veterinary Journal $1994150423-437$. (doi:10.1016/S0007-1935(05)80192-7)

28 Starlinger M, Schiessel R, Hung CR \& Silen W. H+ back diffusion stimulating gastric mucosal blood flow in the rabbit fundus. Surgery 198189 232-236.

29 Holst JJ, Vilsboll T \& Deacon CF. The incretin system and its role in type 2 diabetes mellitus. Molecular and Cellular Endocrinology 2009297 127-136. (doi:10.1016/j.mce.2008.08.012)

30 Verdich C, Flint A, Gutzwiller JP, Naslund E, Beglinger C, Hellstrom PM, Long SJ, Morgan LM, Holst JJ \& Astrup A. A meta-analysis of the effect of glucagon-like peptide-1 (7-36) amide on ad libitum energy intake in humans. Journal of Clinical Endocrinology and Metabolism 200186 4382-4389. (doi:10.1210/jc.86.9.4382)

31 Berglund LM, Lyssenko V, Ladenvall C, Kotova O, Edsfeldt A, Pilgaard K, Alkayyali S, Brons C, Forsblom C, Jonsson A, et al. Glucose-dependent insulinotropic polypeptide stimulates osteopontin expression in the vasculature via endothelin-1 and CREB. Diabetes 201665 239-254.

32 Zhong Q, Bollag RJ, Dransfield DT, Gasalla-Herraiz J, Ding KH, Min L \& Isales CM. Glucose-dependent insulinotropic peptide signaling pathways in endothelial cells. Peptides 200021 1427-1432. (doi:10.1016/S0196-9781(00)00287-4)

33 Koska J, Sands M, Burciu C, D'Souza KM, Raravikar K, Liu J, Truran S, Franco DA, Schwartz EA, Schwenke DC, et al. Exenatide protects against glucose- and lipid-induced endothelial dysfunction: evidence for direct vasodilation effect of GLP-1 receptor agonists in humans. Diabetes 201564 2624-2635. (doi:10.2337/db14-0976)

34 Hattori Y, Jojima T, Tomizawa A, Satoh H, Hattori S, Kasai K \& Hayashi T. A glucagon-like peptide-1 (GLP-1) analogue, liraglutide, upregulates nitric oxide production and exerts anti-inflammatory action in endothelial cells. Diabetologia 201053 2256-2263. (doi:10.1007/s00125-010-1831-8)

35 Lu WJ, Yang Q, Sun W, Woods SC, D'Alessio D \& Tso P. Using the lymph fistula rat model to study the potentiation of GIP secretion by the ingestion of fat and glucose. American Journal of Physiology: Gastrointestinal and Liver Physiology 2008294 G1130-G1138. (doi:10.1152/ajpgi.00400.2007)

36 Meier JJ, Gallwitz B, Kask B, Deacon CF, Holst JJ, Schmidt WE \& Nauck MA. Stimulation of insulin secretion by intravenous bolus injection and continuous infusion of gastric inhibitory polypeptide in patients with type 2 diabetes and healthy control subjects. Diabetes 200453 (Supplement 3) S220-S224. (doi:10.2337/diabetes.53.suppl_3.S220)

37 Svensson AM, Ostenson CG, Efendic S \& Jansson L. Effects of glucagon-like peptide-1-(7-36)-amide on pancreatic islet and intestinal blood perfusion in Wistar rats and diabetic GK rats. Clinical Science 2007112 345-351. (doi:10.1042/CS20060272)

38 Trahair LG, Horowitz M, Hausken T, Feinle-Bisset C, Rayner CK \& Jones KL. Effects of exogenous glucagon-like peptide-1 on the blood pressure, heart rate, mesenteric blood flow, and glycemic responses to intraduodenal glucose in healthy older subjects. Journal of Endocrinology and Metabolism 201499 E2628-E2634. (doi:10.1210/ jc.2014-2475)

39 Yamamoto H, Lee CE, Marcus JN, Williams TD, Overton JM, Lopez ME, Hollenberg AN, Baggio L, Saper CB, Drucker DJ, et al. Glucagonlike peptide-1 receptor stimulation increases blood pressure and heart rate and activates autonomic regulatory neurons. Journal of Clinical Investigation 2002110 43-52. (doi:10.1172/JCI0215595)

40 Mari A, Tura A, Natali A, Laville M, Laakso M, Gabriel R, Beck-Nielsen $\mathrm{H}$, Ferrannini E \& RISC Investigators. Impaired beta cell glucose sensitivity rather than inadequate compensation for insulin resistance is the dominant defect in glucose intolerance. Diabetologia 201053 749-756. (doi:10.1007/s00125-009-1647-6)

Received in final form 20 February 2017

Accepted 3 March 2017

Accepted Preprint published online 3 March 2017 http://www.endocrineconnections.org DOI: 10.1530/EC-17-0015

(2) 2017 The authors Published by Bioscientifica Ltd

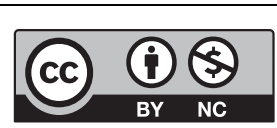

This work is licensed under a Creative Commons Attribution-NonCommercial 4.0 International License. 